\title{
Retrieval of Forest Stem Volume Using VHF SAR
}

\author{
Hans Israelsson, Lars M. H. Ulander, Member, IEEE, Jan I. H. Askne, Member, IEEE, Johan E. S. Fransson, \\ Per-Olov Frölind, Anders Gustavsson, and Hans Hellsten
}

\begin{abstract}
The ability to retrieve forest stem volume using CARABAS (coherent all radio band sensing) SAR images (28-60 MHz) has been investigated. The test site is a deciduous mixed forest on the island of Öland in southern Sweden. The images have been radiometrically calibrated using an array of horizontal dipoles. The images exhibit a clear discrimination between the forest and open fields. The results show that the dynamic range of the backscattering coefficient among the forest stands is higher than what has been found with conventional SAR using microwave frequencies. The backscatter increases with increasing radar frequency. This work shows an advantage compared to higher frequencies for stem volume estimation in dense forests.
\end{abstract}

Index Terms-CARABAS, SAR, stem volume, VHF.

\section{INTRODUCTION}

A NUMBER of investigations have demonstrated that the radar backscattering coefficien of SAR images is correlated with forest biomass [1], [2]. The sensitivity and correlation increase significantl as the radar wavelength increases. This phenomenon has been clearly shown through analyses of images acquired by the PLC-band polarimetric JPL/AIRSAR system. There are also differences of the biomass dependence among different polarizations. Most results indicate a slightly higher sensitivity at cross polarization (HV), but the major difference is found with varying radar wavelengths. The results show that even at the lowest frequency of the JPL/AIRSAR $(440 \mathrm{MHz})$ there is a saturation level where the biomass sensitivity disappears. The saturation levels vary only slightly for different types of forests. The main conclusion from these investigations is that a significan part of the global biomass can not be assessed using SAR images acquired at these frequencies [3]. The canopy attenuation is too strong to permit accurate estimation of high biomass values.

In this paper we have used images from the CARABAS (coherent all radio band sensing) VHF-band SAR system to examine whether a change to lower frequencies would improve the ability to retrieve biomass estimates. By investigating the response from reference targets concealed by a vegetation canopy, it has previously been shown that the canopy pen-

Manuscript received January 22, 1996; revised September 30, 1996. This work was supported by the Swedish Council for Forestry and Agricultural Research and by the Swedish National Space Board.

H. Israelsson and J. Askne are with Chalmers University of Technology, Department of Radio and Space Science, S-412 96 Göteborg, Sweden.

L. M. H. Ulander, P. Frolind, A. Gustavsson and H. Hellsten are with the Defence Research Establishment, Department of Sensor Technology, S-581 11 Linköping, Sweden.

J. E. S. Fransson is with the Swedish University of Agricultural Sciences, Department of Forest Resource Management and Geomatics, S-901 83 Umeå, Sweden.

Publisher Item Identifie S 0196-2892(97)00854-1. etration is higher in CARABAS images than in SAR images using higher radar frequencies [4], [5].

CARABAS has been developed by the Swedish Defence Research Establishment (FOA) and the firs radar tests were conducted in 1992. It is a wide band SAR system which operates at HH-polarization and between 20-90 MHz. In Fig. 1 the CARABAS aircraft is shown in flight The SAR processing algorithm assumes a semi-circular illumination pattern that is realized by the two antenna tubes that are trailed behind the aircraft. A more extensive summary of the system and the SAR processing algorithm can be found in [6], [7]. The frequency band corresponds to wavelengths between 3.3 and $15 \mathrm{~m}$, which gives the system a good ability to penetrate the forest canopy and image the bulk characteristics of the vegetation. The resolution cell includes a limited number of scatterers at VHF. Thus, a reduced speckle level in the fina SAR image is expected, compared to images from conventional microwave SAR systems. In this study, the forest stem volume information content of CARABAS images is investigated.

\section{TEST Site DESCRIPTION}

The CARABAS fligh campaign was conducted during October 1992. Transmitted frequencies between 28 and 60 $\mathrm{MHz}$ were used in the SAR processing. The data were split into four consecutive $8 \mathrm{MHz}$ images and Doppler bandwidth was limited by frequency-domain filtering.I should be noted that no motion compensation for the fligh path was possible due to lack of adequate positioning equipment in the aircraft. Furthermore, the radio interference rejection has been carried out using a simplifie algorithm, which only suppresses part of the interference. The spatial resolutions of the images are $10 \mathrm{~m}$ and $5 \mathrm{~m}$ in slant range and cross range, respectively.

A test site was chosen on the island of Öland, located in the Baltic Sea outside the Southeast shore of the Swedish mainland at a latitude of $56^{\circ} 14^{\prime}$ and a longitude of $16^{\circ}$ $26^{\prime}$, Fig. 2. Reference targets were deployed and ground truth was collected. The area has no variation in elevation and the effect of topography is therefore insignificant It consists of a mixed deciduous forest surrounded by a large open field The predominant species are oak (Quercus robur), birch (Betula sp.), and alder (Alnus glutinosa). The fiel layer is mainly covered with different grass and herb species and the soil type is morain. Using aerial photographs the forested area was divided into 12 approximately homogenous stands representing different types of deciduous forest with various stem volumes. The stem volume represents the volume in 


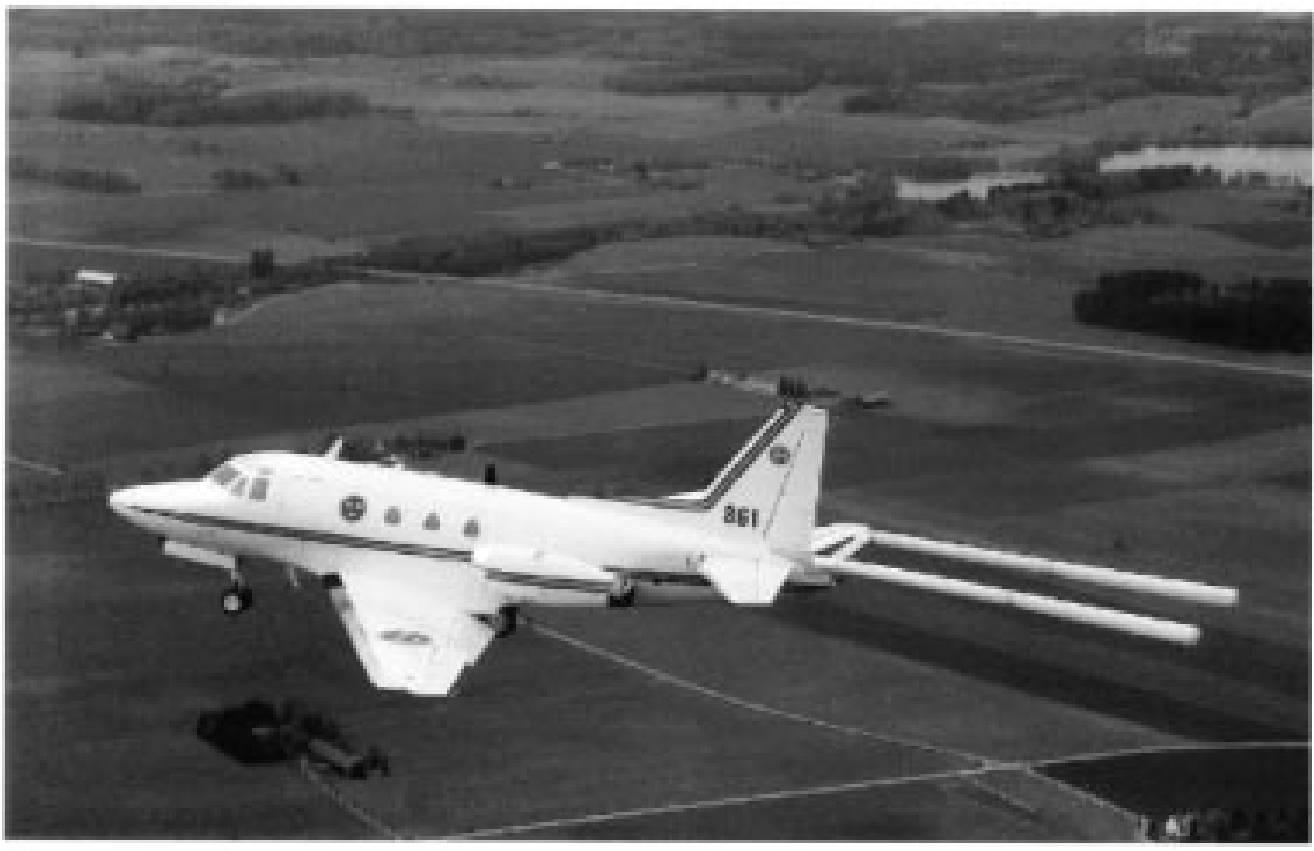

Fig. 1. The Sabreliner aircraft with the CARABAS antenna system deployed (courtesy of FMV:Prov).

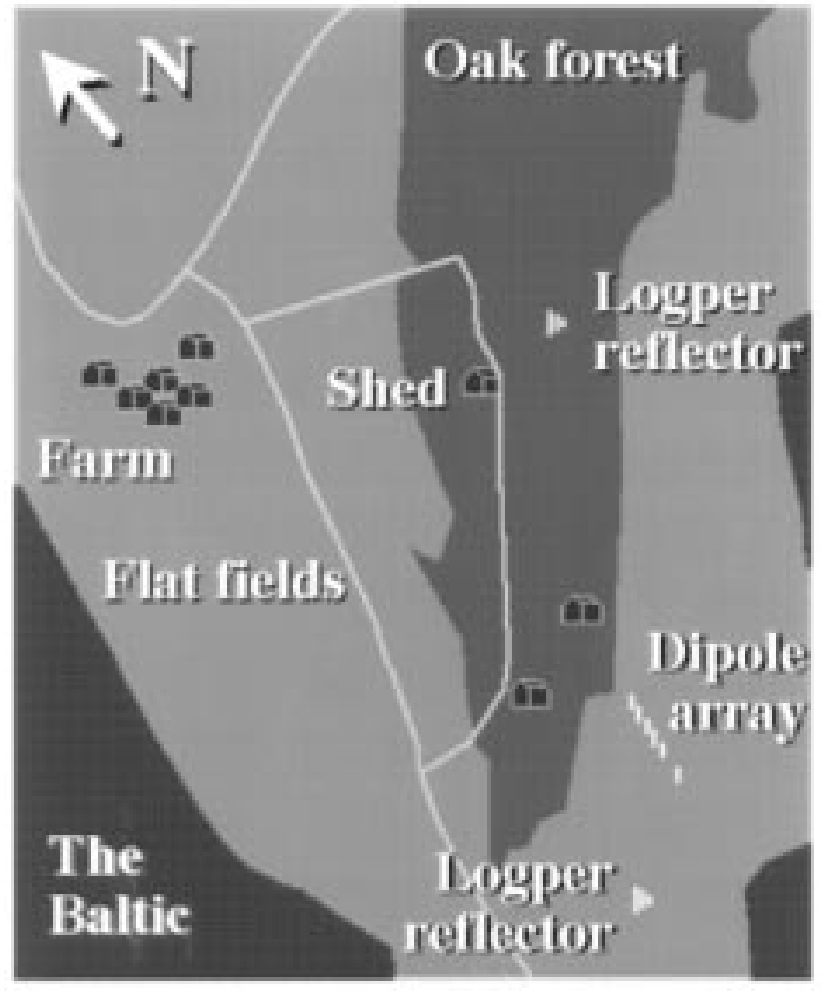

Fig. 2. A schematic map of the $4 \times 3 \mathrm{~km}$ Ottenbylund test site, located on the southern tip of Öland. Different test targets were deployed both in the open and in the forest for radiometric calibration and foliage attenuation measurements.

cubic meters per hectare $\left(\mathrm{m}^{3} / \mathrm{ha}\right)$ of all trees in a certain stand including bark but excluding branches and stumps, whereas all above ground parts of the trees usually are included in the biomass measure. The delineated stands are between $2-12$ hectares in size with stem volumes in the range of 20 to $210 \mathrm{~m}^{3} /$ ha having a tree species mixture of $60 \%$ oak, $19 \%$ birch, $18 \%$ alder, and 3\% other species. The forest stem volume of each stand was estimated objectively in the fiel by relascope sampling [8]. The relascope points were distributed in a randomly located systematic grid, giving an average of fiv sample points per stand. The HorvitzThompson estimator [9] was used to calculate the stem volume of the stands. A ratio estimator of stem volume using basal area as an ancillary variable was applied. A rough measure of the precision of the stem volume estimates was calculated by averaging the variance estimates from the individual stands. The relative precision in terms of standard error was found to be $13 \%$.

Fig. 3 shows a comparison of a C-band ERS- 1 image and a CARABAS image from the area described in Fig. 2. The ERS-1 PRI (PRecision Image level) scene was acquired in September 1992: one month before the CARABAS campaign. The CARABAS image was processed with a fraction of the bandwidth and pre-summed in azimuth to obtain a similar spatial resolution to ERS-1 image. The incidence angle for the two images is however quite different, $25^{\circ}$ for ERS- 1 versus $60^{\circ}$ for CARABAS. The deciduous forest is found in the middle of the two images, surrounded by open field The forest is easily recognized in the CARABAS image, while it is difficul to discriminate the forest from open fiel in the ERS-1 image. There are some single trees standing on the open fiel that can be found in the CARABAS image. The open field which mainly is a meadow land, acts as a rough surface at $\mathrm{C}$-band and produces a backscattered signal of the same magnitude as the forest canopy. The sheds, pointed out in Fig. 2, are concealed by the forest in the ERS-1 image but can be identifie as bright spots in the CARABAS image. The smooth shoreline in the lower-left part can be identifie in the ERS-1 image but is invisible for CARABAS. 

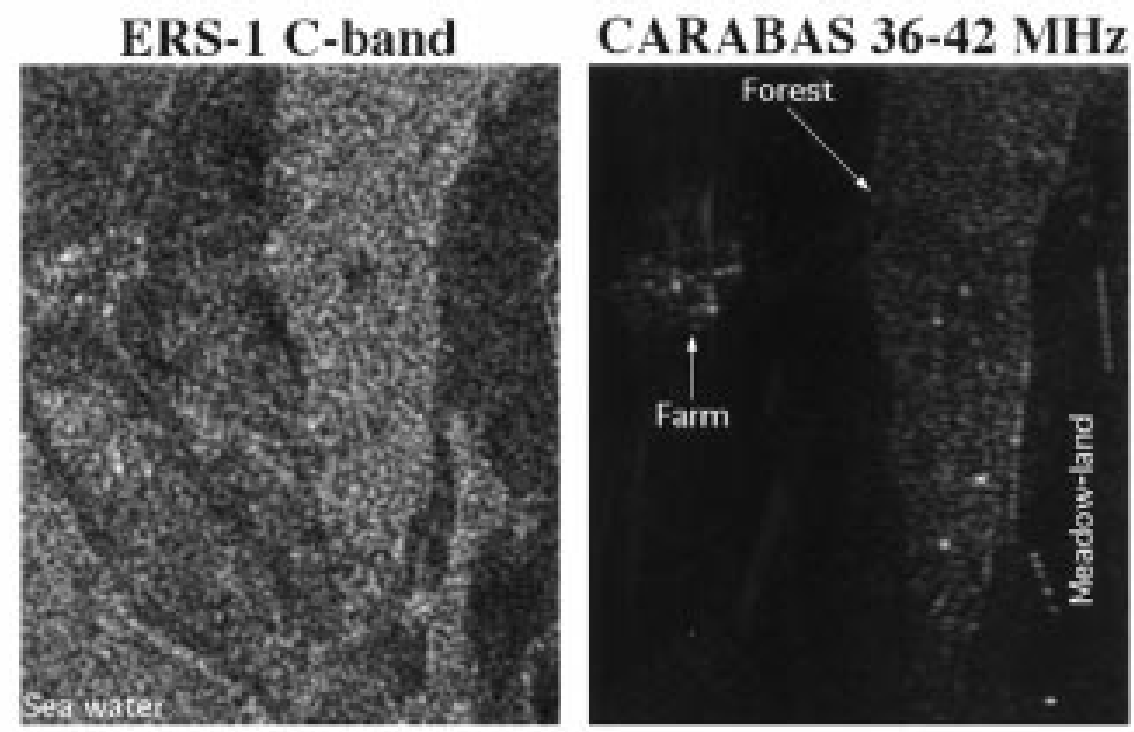

Fig. 3. A comparison of a CARABAS image (right) and an ERS-1 image (@ ESA 1992 ERS-1-R) from the Ottenbylund test site is shown. A fraction of the available signal bandwidth has been used in the SAR processing of the CARABAS data, to obtain a spatial resolution of the same order as for ERS-1. The CARABAS radar is illuminating the scene from the right hand side of the image.

\section{RADIOMETRIC CALIBRATION}

An array of near-resonant horizontal dipoles was deployed in the open fiel adjacent to the forest, see Figs. 2 and 3. The sizes of the dipoles were all the same $(3.3 \mathrm{~m}$ length, $2.5 \mathrm{~cm}$ diameter) but the height above ground varied between 1-5 $\mathrm{m}$ in order to study the effect of ground interaction. The latter is, to firs order, due to interference between the direct and ground-reflecte wave, which results in destructive interference close to the ground. For increasing height, however, it gives an oscillating radar cross section (RCS) corresponding to constructive and destructive interference. A MoM (method of moments) model of the RCS including higher order ground interaction has been developed and used to determine the radiometric calibration constant [10]. The accuracy of the latter is estimated to $\pm 1 \mathrm{~dB}$ for the two middle and $\pm 2 \mathrm{~dB}$ for the two outer $8 \mathrm{MHz}$ bands. Since the dipole length was optimized for the middle bands, the accuracy is less at the outer bands.

\section{RESULTS}

As shown in Fig. 3, the forested areas exhibit an apparently stronger backscattering coefficien than the surrounding field in the CARABAS image. Among the different forest stands there is an evident correlation between the backscattering coefficien and the forest stem volume. In Figs. 4-7 results from the twelve stands are presented. The incidence angles among the forest stands are $60-65^{\circ}$. The lack of forest stands with higher stem volume than $210 \mathrm{~m}^{3} / \mathrm{ha}$ unfortunately makes determination of a saturation level impossible in this case, but should be investigated in future work.

In a previous analysis of data from the JPL/AIRSAR of a similar forest, the ability to detect stem volume from the backscattering coefficien was investigated [11]. The forest was located in the Netherlands and was dominated by mainly poplar. A sensitivity to stem volume was found up to a

\section{8-36 $\mathrm{MHz}$}

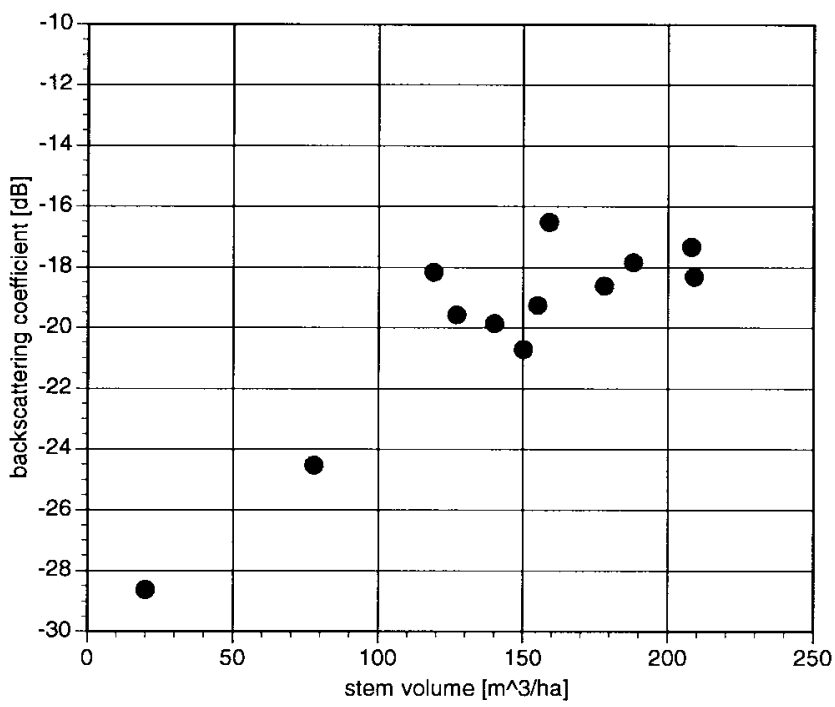

Fig. 4. Comparison of the backscattering coefficien at $28-36 \mathrm{MHz}$ and forest stem volume. The accuracy of the backscattering coefficient is estimated to $\pm 2 \mathrm{~dB}$.

certain saturation level where the backscattering coefficien showed no increase when increasing the forest stem volume. Similar behavior has been found by several other authors studying other types of forested areas. In Fig. 8, the dynamic ranges between $0-200 \mathrm{~m}^{3} / \mathrm{ha}$ are examined. Most studies indicate stem volume saturation levels slightly above 200 $\mathrm{m}^{3} /$ ha at P-band. The PLC-band results were obtained using the JPL/AIRSAR data from the Dutch test site. The dynamic range was determined from linear regression. The increasing dynamic range as the frequency decreases from $5 \mathrm{GHz}$ to $440 \mathrm{MHz}$ is well known. These results additionally show a higher dynamic range among the CARABAS frequencies. 
$37-44 \mathrm{MHz}$

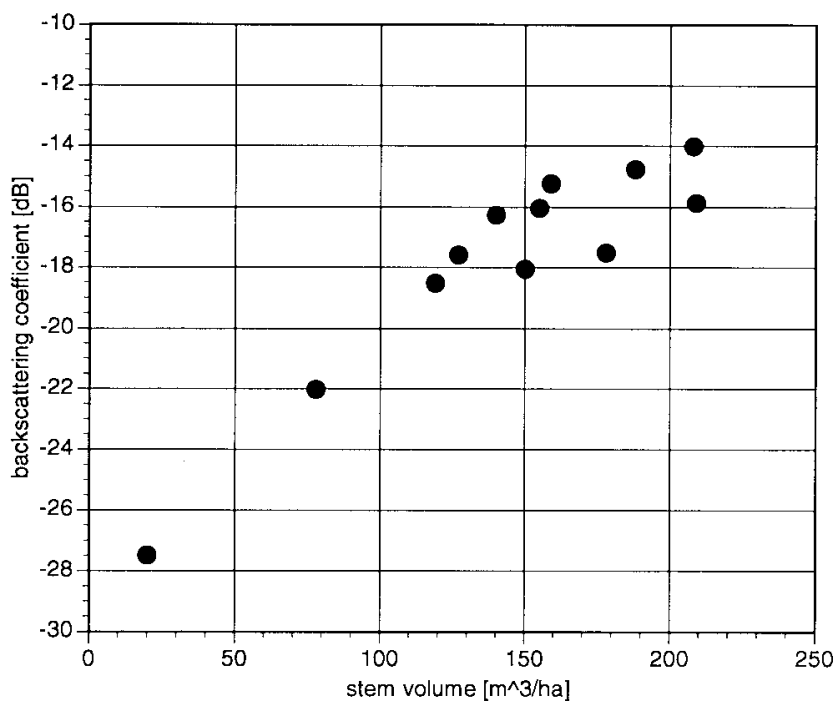

Fig. 5. Comparison of the backscattering coefficien at $37-44 \mathrm{MHz}$ and forest stem volume. The accuracy of the backscattering coefficient is estimated to $\pm 1 \mathrm{~dB}$.

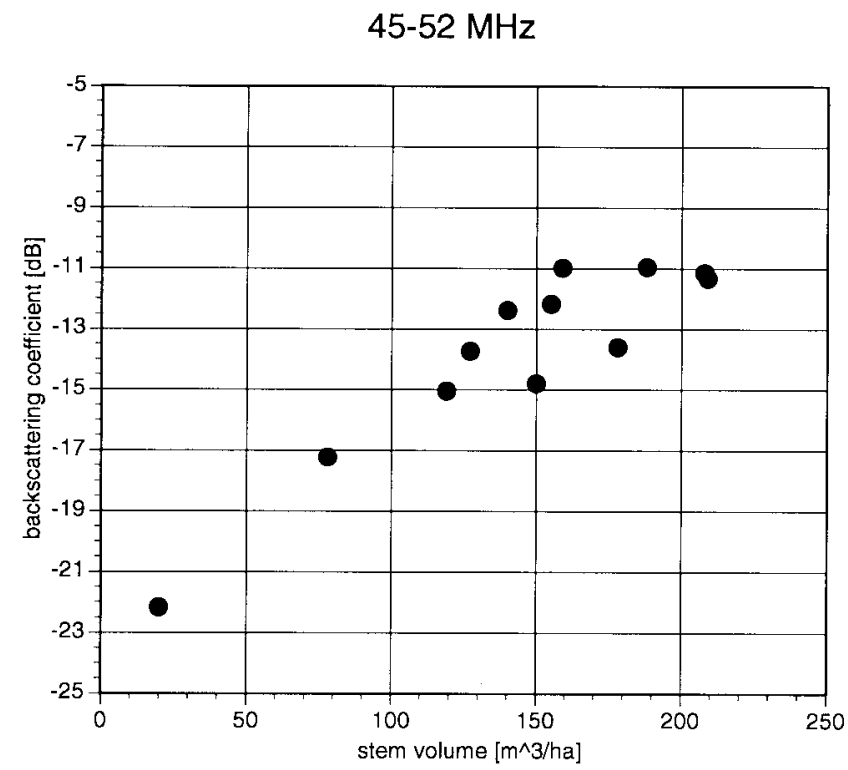

Fig. 6. Comparison of the backscattering coefficien at $45-52 \mathrm{MHz}$ and forest stem volume. The accuracy of the backscattering coefficient is estimated to $\pm 1 \mathrm{~dB}$.

The CARABAS images from the higher frequencies exhibit slightly smaller dynamic range.

Since the CARABAS frequencies are significantl lower than the ones that are used by conventional SAR systems, different electromagnetic scattering mechanisms are expected. Due to the $\mathrm{HH}$ polarization, horizontal primary branches are expected to dominate the backscattering. Also, reflectio from the ground followed by scattering from the canopy might contribute to the total backscattering. The trunk-ground and the branch-ground scattering are theoretically of the same order of magnitudes. Penetration into the ground and backscattering from roots is not expected to contribute significantl in this
$53-60 \mathrm{MHz}$

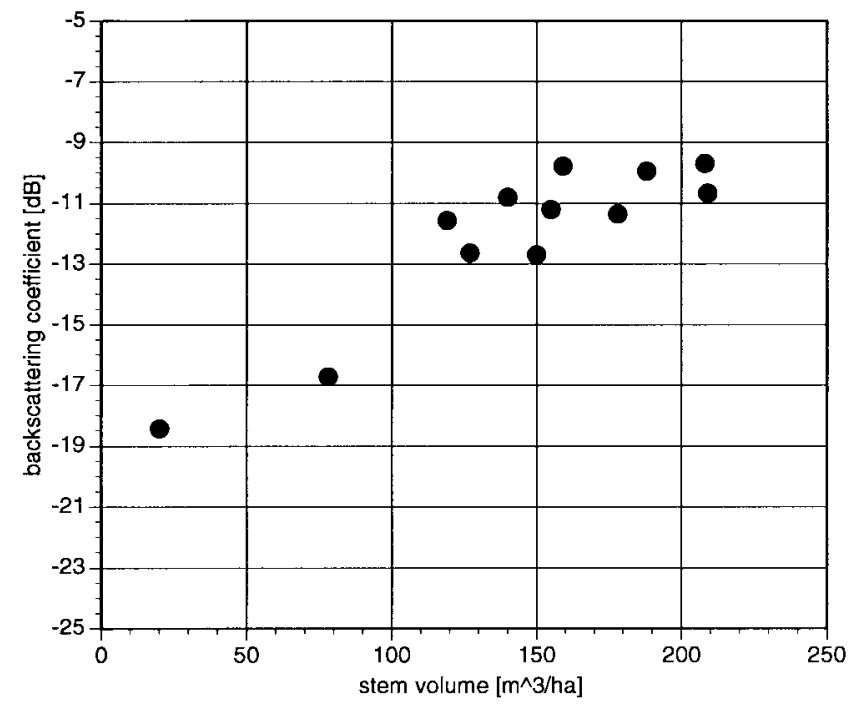

Fig. 7. Comparison of the backscattering coefficien at 53-60 MHz and forest stem volume. The accuracy of the backscattering coefficient is estimated to $\pm 2 \mathrm{~dB}$.

dynamic range within $0-200\left[\mathrm{~m}^{3} / \mathrm{ha}\right]$

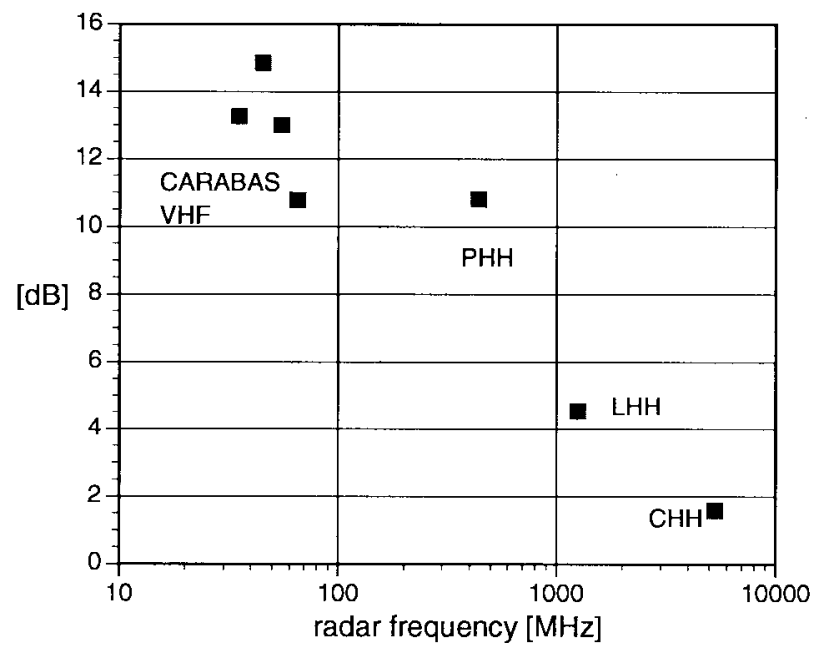

Fig. 8. The dynamic ranges of the backscattering coefficient as the stem volume increases between $0-200 \mathrm{~m}^{3} / \mathrm{ha}$ are compared at different frequencies.

case. In a current project, modeling of the different scattering mechanisms is analyzed in more detail.

The experiences gained from the CARABAS system are currently used in the development of a new upgraded CARABAS II system [12], now nearing completion. Field campaigns, including forest biomass investigations, will take place during 1997.

\section{CONCLUSION}

Radiometrically calibrated data from the CARABAS VHF SAR system has been investigated in a test area of a mixed deciduous forest. The SAR images provide excellent discrimination of the forest and open field They also contain 
information about the forest stem volume. The dynamic range of the backscattering coefficien as the forest stem volume is increasing from $0-200 \mathrm{~m}^{3} / \mathrm{ha}$ is clearly higher than the corresponding analyses of images from SAR systems using higher frequencies. An increase in backscatter is observed for increasing stem volume and radar frequency.

\section{ACKNOWLEDGMENT}

The authors would like to thank the reviewers for their comments.

\section{REFERENCES}

[1] T. Le Toan, A. Beaudoin, J. Riom, and D. Guyon, "Relating forest biomass to SAR data," IEEE Trans. Geosci. Remote Sensing, vol. 30, pp. 403-411, 1992

[2] M. C. Dobson, F. T. Ulaby, L. E. Pierce, T. L. Sharik, K. M. Bergen, J. Kellendorfer, J. R. Kendra, E. Li, Y. C. Lin, A. Nashashiba, K. Sarabandi, and P. Siqueira, "Estimation of forest biophysical characteristics in northern michigan with SIR-C/X-SAR," IEEE Trans. Geosci. Remote Sensing, vol. 33, pp. 877-895, 1995.

[3] M. L. Imhoff, "Radar backscatter and biomass saturation: Ramification for global biomass inventory," IEEE Trans. Geosci. Remote Sensing, vol. 33, pp. 511-518, 1995.

[4] B. T. Binder, M. F. Toups, S. Ayasli, and E. M. Adams, "SAR foilage penetration phenomenology of tropical rain forests and northern U.S. forest," in Proc. IEEE 1995 Int. Radar Conf., Alexandria, VA.

[5] H. Hellsten, P.-O. Frölind, A. Gustavsson, T. Jonsson, B. Larsson, G. Stenström, B. T. Binder, M. Mirkin, and S. Ayasli, "Ultra-wideband VHF SAR—Design and measurements," in SPIE, Orlando, FL, 1994, vol. 2217.

[6] A. Gustavsson, P. O. Frölind, H. Hellsten, T. Jonsson, B. Larsson, and G. Stenström, "The airborne VHF SAR system CARABAS," in Proc. IGARSS'93, Tokyo, Japan, 1993.

[7] H. Hellsten, "Inverse scattering analysis of diffraction limited SAR," IEEE Trans. Antennas Propagat., vol. 38, pp. 1517-1522, 1990.

[8] W. Bitterlich, The Relascope Idea. Farnham: Commonwealth Agricultural Bureaux, 1984

[9] D. Raj, Sampling Theory. New York: McGraw-Hill, 1968.

[10] L. M. H. Ulander and Z. Sipus, "RCS of dipoles used for SAR calibration," in Proc. EUSAR'96, Königswinter, Germany, 1996.

[11] H. Israelsson, J. Askne, and R. Sylvander, "Potential of SAR for forest bole volume estimation," Int. J. Remote Sensing, vol. 15, pp. 2809-2826, 1994.

[12] H. Hellsten, L. M. H. Ulander, A. Gustavsson, and B. Larsson, "Development of VHF CARABAS II SAR," in SPIE, Orlando, FL, 1996, vol. 2747

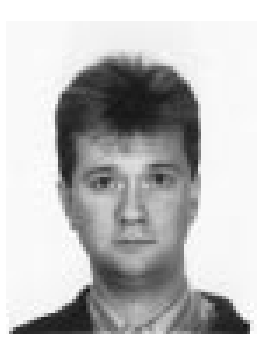

Hans Israelsson was born in Olofström, Sweden He received the M.Sc. degree in engineering physics and the technical licentiate degree in radio and space science at Chalmers University of Technology, Göteborg, Sweden, in 1990 and 1993, respectively. $\mathrm{He}$ is currently pursuing the Ph.D. degree at the same university.

Since 1995, he has been with the Core Unit Antenna Systems at Ericsson Microwave Systems in Mölndal, Sweden. His main interest concerns models of electromagnetic scattering.

Lars M. H. Ulander (M'91), for a photograph and biography, see this issue, p. 35 .

Jan I. H. Askne (S'63-M'65), for a photograph and biography, see this issue, p. 35 .

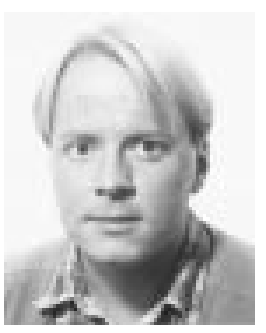

Johan E. S. Fransson was born in Karlshamn, Sweden, in 1967. He received the M.Sc. degree in forestry from the Swedish University of Agricultural Sciences, Umea, in 1992.

Since 1992 he has been with the Department of Forest Resource Management and Geomatics at the same university, completing the Ph.D. degree in remote sensing. His main research interest concerns analysis of SAR data for forestry applications. In 1995 he received the International Space University Certificat from the Royal Institute of Technology in Stockholm, Sweden.

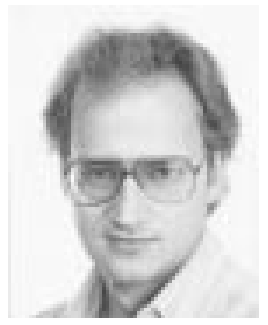

Per-Olov Frölind was born in Norrköping, Sweden In 1985 he received the M.Sc. degree in physics from Linköping University, Sweden.

In 1985 he joined the Defense Research Establishment (FOA) to work with the CARABAS project. He participated in the study of propagation effects and coherent integration in the VHF band. He is now responsible for the software development of the ground-based SAR processor algorithm. His current interests include advanced signal processing techniques for VHF SAR, interferometry, and other multistatic image configurations

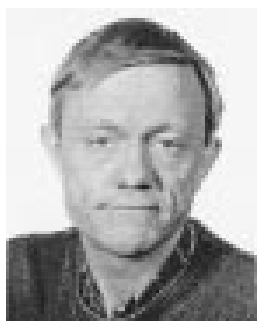

Anders Gustavsson was born in Linköping, Sweden. He received the M.Sc. degree in applied physics and electrical engineering from Linköping University in 1982.

In 1982 he joined the Defense Research Establishment (FOA) to work with the development of a computer based SAR processor for microwave systems. He has participated in the Swedish research program using SAR data to monitor sea ice conditions, including several SAR experiments in the Baltic Sea with SAR data from both airborne systems and ERS-1. He has been with the CARABAS project since 1990 and his current work is in inversion algorithms for wide band SAR image reconstruction.

Mr. Gustavsson was presented with an IEEE Prize Paper Award for a manuscript on the CARABAS sensor in 1993.

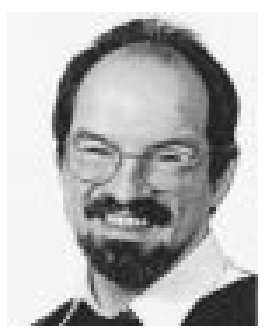

Hans Hellsten was born in Stockholm, Sweden. He received the Ph.D. degree in theoretical physics from the University of Stockholm.

Since 1981 he has worked at the Defence Research Establishment (FOA) in the fiel of radar, firs with antenna development for millimeter waves and, since 1984, with radar systems theory in general and synthetic aperture radar in particular. In 1985 he originated the ideas of ultra-wide band radar, the use of VHF frequencies and their combination with SAR to obtain ground resolution of wavelength order. He has since had the main responsibility for the considerable effort done in Sweden to realize these technologies in practical systems. In this effort he has produced numerous inventions, several of these patented worldwide. He is currently a Director of Research and Head of the CARABAS Laboratory of FOA.

Dr. Hellsten was awarded the gold medal from the Swedish Academy of Engineering Science (IVA) for outstanding work in 1994. 